\title{
Fragmentation of the DNA Repair Enzyme, OGG1, in Mouse Nonparenchymal Liver Cells by Arsenic Compounds
}

\author{
Takeshi Hirano ${ }^{1,2}$, Kazuaki Kawai ${ }^{1}$, Yuko Ootsuyama ${ }^{1}$ and Hiroshi Kasai ${ }^{1,3}$ \\ ${ }^{1}$ Department of Environmental Oncology, University of Occupational and Environmental Health, Japan, Fukuoka, Japan
}

(Received March 7, 2006; Accepted April 14, 2006)

\begin{abstract}
Our previous work demonstrated that arsenic compounds increased 8-hydroxyguanine (8-OH-Gua) in the DNA of cultured human cells (A549) and reduced the endonuclease nicking activity for $8-\mathrm{OH}-\mathrm{Gua}$, suggesting that arsenic compound-induced carcinogenesis was the consequence of the inhibition of DNA repair. However, the exact mechanism by which the repair systems were disturbed was unknown. To elucidate the mechanism, we analyzed mouse 8-oxoguanine DNA glycosylase 1 (mOGG1) expression in mouse nonparenchymal liver cells, NCTC, treated with arsenic compounds (arsenic trioxide, sodium arsenite, and sodium hydrogen arsenate). We detected a cleaved form of mOGG1 (35 kDa) in addition to normal mOGG1 (type 1a, $38 \mathrm{kDa}$ ) in NCTC treated with arsenic compounds. These results are similar to our previous results which showed that fragmentation of mOGG1 by etoposide was related to caspase-dependent apoptosis, and was accompanied by increased 8-OH-Gua accumulation. Taken together, our results suggested that arsenic compounds might increase 8-OH-Gua accumulation by inhibiting $8-\mathrm{OH}-\mathrm{Gua}$ repair, due to mOGG1 cleavage.
\end{abstract}

Key words: mOGG1, arsenic compounds, 8-hydroxyguanine

\section{Introduction}

Arsenic compounds are known to be toxic or carcinogenic to humans and are associated with various diseases, such as cancer, hepatic damage and arteriosclerosis. In particular, they are associated with the development of several kinds of tumors, including lung, skin, kidney, bladder and liver tumors (1-5). Recently, arsenic trioxide was shown to induce DNA damage, such as 8-hydroxyguanine (8-OH-Gua) and DNA strand breaks, in cultured human cells $(6,7)$. It was also reported that the urinary $8-\mathrm{OH}-\mathrm{dG}$ level is increased with exposure to arsenic compounds $(8,9)$. The DNA damage induced by arsenic compounds was extensively investigated, and the contributions of reactive oxygen species (ROS) and nitric oxide generated by arsenic compounds to the carcinogenic mechanisms have been suggested (10-12). However, the exact role of DNA damage in arsenic compound-related carcinogenesis is still unclear.

8-OH-Gua is a major premutagenic form of oxidative DNA damage that induces GC to TA transversion type point mutation in DNA (13). Therefore, GC to TA point mutations, which are often detected in various cancer cells, may be induced by ROS. In order to prevent such mutations, several repair systems are ubiquitously present, from bacteria to human $(14,15)$. However, when excessive amounts of ROS are generated or the repair systems are inhibited, 8-OH-Gua might accumulate in nuclear or mitochondrial DNA, leading to the subsequent carcinogenesis, because the accumulation level of $8-\mathrm{OH}-\mathrm{Gua}$ depends on the balance between $8-\mathrm{OH}-\mathrm{Gua}$ generation and repair.

Recent studies revealed that heavy metals, such as cadmium chloride, reduced DNA repair activity $(16,17)$. Arsenic compounds also interact with DNA repair systems, leading to the accumulation of DNA damage (18). Furthermore, it was reported that metabolites of inorganic arsenic, monomethylarsonous- and dimethylarsinous acids, inhibit the activity of the Fpg protein (9), which functions as a glycosylase and an AP-lyase and also has a 5'-terminal deoxyribosephosphate excising activity (14). Hence, it is likely that $8-\mathrm{OH}-\mathrm{Gua}$ repair might be inhibited by arsenic compounds, leading to an accumulation of $8-\mathrm{OH}-\mathrm{Gua}$ that could be responsible for carcinogenesis. However, the detailed mechanisms of the inhibition of DNA repair systems are still unknown.

The present study was performed to examine the expression of a DNA repair protein, mouse 8-oxoguanine DNA glycosylase 1 (mOGG1). Insights relevant to the inhibition mechanisms of DNA repair in cells treated with arsenic compounds are discussed.

${ }^{2}$ Present address: Graduate School of Environmental Engineering, University of Kitakyushu, Kitakyushu, Fukuoka, 808-0135, Japan ${ }^{3}$ Correspondence to: Hiroshi Kasai, Department of Environmental Oncology, University of Occupational and Environmental Health, Japan, Kitakyushu, Fukuoka, 807-8555, Japan. Tel: +81-93-6031611, Fax: +81-93-601-2199, E-mail: h-kasai@med.uoeh-u.ac.jp 


\section{Materials and Methods}

Cell culture and treatment with arsenic compounds: NCTC, nonparenchymal liver cells, were obtained from the Health Science Research Resources Bank (HSRRB, Osaka, Japan) and were cultured in NCTC135 medium (ICN Biomedicals Inc., Ohio) with $10 \%$ horse serum. When the cells were $\sim 70 \%$ confluent, arsenic compounds (arsenic trioxide, sodium arsenite, and sodium arsenate), cadmium chloride as a reference, and dimethyl sulfoxide (DMSO) as a control were added into the culture medium to a final concentration of $10 \mu \mathrm{M}$ each. After 24 and $48 \mathrm{~h}$ of cultivation, the cells were harvested, washed with sterile PBS, and subjected to analyses.

Sample preparation and Western blotting: NCTC were homogenized with a Potter-type homogenizer in cold buffer $(50 \mathrm{mM}$ Tris- $\mathrm{HCl}, 50 \mathrm{mM} \mathrm{KCl}, 3 \mathrm{mM}$ EDTA, $5 \mathrm{mM}$ magnesium acetate, and $3 \mathrm{mM} \beta$-mercaptoethanol) containing $5 \mu \mathrm{g} / \mathrm{mL}$ each of protease inhibitors (leupeptin, antipain, pepstatin, and chymostatin). The homogenates were centrifuged (12000 g, $30 \mathrm{~min})$, and the supernatants were used for Western blot analysis. The Western blotting method was described elsewhere. Protein concentrations were determined using a Bio-Rad Protein Assay kit (Bio-Rad, Richmond, CA). Proteins $(40 \mu \mathrm{g})$ were fractionated on $4-12 \%$ SDSpolyacrylamide gels (NuPAGE, NOVEX, CA), and blotted onto PVDF membranes (Millipore, MA). The filters were blocked with a buffer $(150 \mathrm{mM}$ Tris- $\mathrm{HCl}$, $\mathrm{pH}$ 7.6, containing Triton $\mathrm{X}-100$ and bovine serum albumin) overnight at $37^{\circ} \mathrm{C}$, and then were incubated with anti-mOGG1 antiserum overnight at $37^{\circ} \mathrm{C}$. After two washes, the blots were incubated with an alkaline phosphatase-coupled secondary antibody (EY Laboratories, Inc., CA) at $37^{\circ} \mathrm{C}$ for $3 \mathrm{~h}$. The antigen-antibody complexes were visualized with a BCIP-NBT solution kit (Nakalai Tesque, Inc., Kyoto). The anti-mOGG1 antiserum was prepared as described in our previous work (19). The amino acid sequence of the peptide used as the antigen was QSFRWKEOSP (aa 43-52).

Endonuclease nicking assay: The base excision repair activity was assayed by using a previously described method. Briefly, the cells were homogenized in cold buffer $(50 \mathrm{mM}$ Tris- $\mathrm{HCl}, 50 \mathrm{mM} \mathrm{KCl}, 3 \mathrm{mM}$ EDTA, $5 \mathrm{mM}$ magnesium acetate, and $3 \mathrm{mM} \beta$-mercaptoethanol) containing $5 \mu \mathrm{g} / \mathrm{mL}$ each of protease inhibitors (leupeptin, antipain, pepstatin, and chymostatin), and the lysates were centrifuged $(12000 \mathrm{~g}, 30 \mathrm{~min})$ to obtain crude extracts. The extracts were incubated with a 22-mer, fluorescently labeled, synthetic oligonucleotide containing an 8-OH-Gua residue in its sequence. These mixtures were electrophoresed on a $20 \%$ denaturing polyacrylamide gel. The excised fragments, generated as a consequence of base excision repair activity, were analyzed with a Pharmacia ALF DNA sequencer
(Fragment Manager, Ver. 1.1; Amersham Pharmacia Biotech, Uppsala, Sweden).

Analysis of 8-OH-Gua in cellular DNA: The assay for measuring the 8-OH-Gua levels was described elsewhere. Briefly, NCTC treated with $10 \mu \mathrm{M}$ arsenic trioxide for $24 \mathrm{~h}$ were divided into two cell groups: adherent cells and floating cells. The cellular genomic DNA of each cell group was isolated by the sodium iodide method, using a DNA Extraction WB Kit (Wako Pure Chemical Industries, Ltd., Japan). For cell homogenization, a lysis solution containing $1 \mathrm{mM}$ desferal (deferoxamine mesylate, Sigma Chemical Co., MO, USA) was used. The isolated DNA was digested with nuclease P1 (Yamasa Corp., Choshi, Japan) and alkaline phosphatase (Roche Diagnostics $\mathrm{GmbH}$, Mannheim, Germany) to obtain a deoxynucleoside mixture. The solution was filtered with an UltrafreeProbind filter (Millipore, Bedford, MA) and was injected into a high-performance liquid chromatography (HPLC) column (Shiseido Capcell Pak C18 MG) equipped with an electrochemical detector (ECD) (Coulochem II, ESA, USA). The 8-OH-Gua value in the DNA was calculated as the number of $8-\mathrm{OH}-\mathrm{Gua}$ per $10^{6}$ guanine (Gua).

Statistical analysis: Analyses were performed using the Stat View-J 4.5 program (Berkeley, CA). Statistical significance was determined by the one-way analysis of variance (ANOVA), followed by the Scheffe test.

\section{Results}

Cell viability: As shown in Fig. 1, the viability of the NCTC treated with arsenic trioxide and sodium arsenite significantly decreased during the $48 \mathrm{~h}$ treatment, as compared to the DMSO-treated control cells. The floating cells revealed the significant reduction in viability with these compounds.

Endonuclease nicking assay: We analyzed endonuclease nicking activity using 8-OH-Gua containing DNA to examine whether arsenic compounds inhibit 8$\mathrm{OH}-\mathrm{Gua}$ repair activity. We observed that endonuclease nicking activities decreased in a crude extract from arsenic trioxide-treated cells during 48 h (Fig. 2).

Analyses of mOGG1 expression: We analyzed the mOGG1 protein expression in the cells treated with arsenic trioxide, sodium arsenite, sodium hydrogen arsenate, cadmium chloride, and DMSO as a control. Fragmentation of the $38 \mathrm{kDa}$ mOGG1 to the $35 \mathrm{kDa}$ form was detected in the cells treated with arsenic trioxide for 24 and $48 \mathrm{~h}$, and with sodium arsenite for $48 \mathrm{~h}$, but not with sodium hydrogen arsenate, cadmium chloride, and DMSO (Fig. 3). It is worth mentioning that the fragmentation of mOGG1 was detected in the cells treated with arsenic trioxide even at $24 \mathrm{~h}$, suggesting that mOGG1 fragmentation might occur at the early 
a.
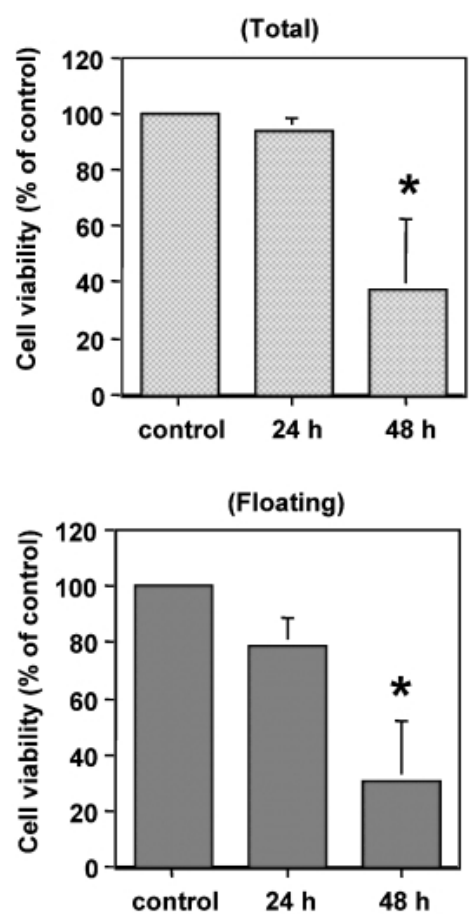

b.
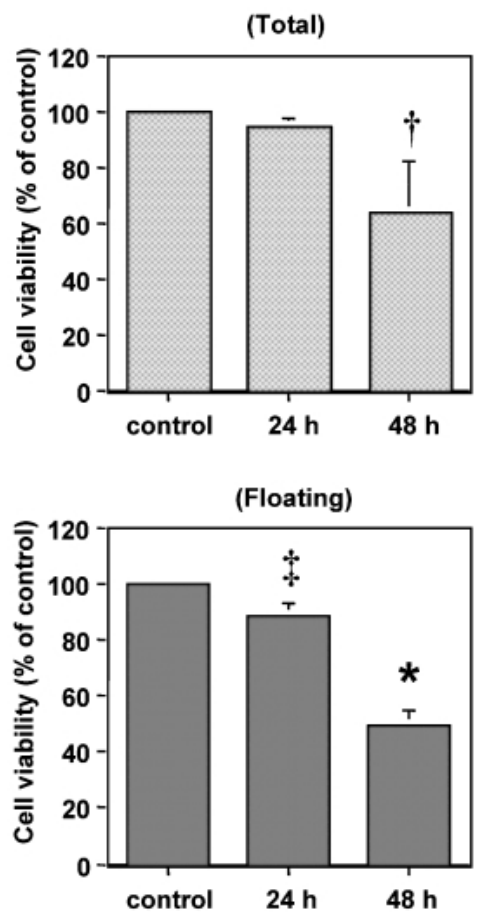

Fig. 1. Viability of NCTC. (a) The viabilities of total cells and floating cells of arsenic trioxide (10 $\mu \mathrm{M})$-treated NCTC (24 and $48 \mathrm{~h})$. The ratio (\%) of the viability of treated cells to that of the DMSO-treated control cells is shown. (b) The viability of total cells and floating cells of sodium arsenite $(10 \mu \mathrm{M})$-treated NCTC $(24$ and $48 \mathrm{~h})$. Cell viability was assayed by means of the trypan blue exclusion test. The volume of DMSO was equal to that of the arsenic trioxide or sodium arsenite solutions. Means $\pm \mathrm{SD}, \mathrm{n}=4-5$. ${ }^{*} \mathrm{p}<0.0001 ; \uparrow \mathrm{p}=0.0007 ; \mathrm{t} \mathrm{p}=0.0017$; significantly lower than the control group.

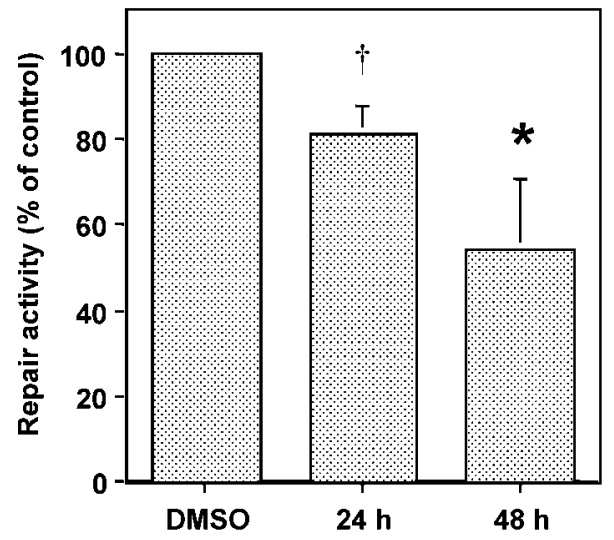

Fig. 2. 8-OH-Gua repair activity in NCTC treated with arsenic trioxide. Repair activity was analyzed in the cells treated with arsenic trioxide by an endonuclease nicking assay. The value of the repair activity of treated cells is expressed as the ratio (\%) to that of the DMSO-treated control. Means $\pm \mathrm{SD}, \mathrm{n}=6 .{ }^{*} \mathrm{p}<0.0001 ; \dagger \mathrm{p}=0.022$; significantly lower than the control group.

stage of the inhibition of mOGG1 activity.

Accumulation of 8-OH-Gua in NCTC DNA: As arsenic compounds reportedly generate reactive oxygen species (ROS), the 8-OH-Gua level might increase in the
DNA of arsenic compound-treated cells. Cultured NCTC cells were treated with $10 \mu \mathrm{M}$ arsenic trioxide for $24 \mathrm{~h}$, and the cells were divided into adherent and floating cell populations. We detected a significant increase in 8-OH-Gua in the DNA of the floating NCTC-cells in comparison with the control cells at $24 \mathrm{~h}$ (Fig. 4).

\section{Discussion}

Since 8-OH-Gua is a form of oxidative DNA damage that induces GC to TA point mutations in DNA, it is believed to be related to carcinogenesis. In this context, in order to reduce cancer risk it is important to prevent 8-OH-Gua accumulation in nuclear DNA. For this purpose, understanding the mechanisms of $8-\mathrm{OH}-\mathrm{Gua}$ generation is an important issue. As for arsenic compounds, many reports have indicated that they increased oxidative DNA damage in cultured cells $(6,7)$. For example, hydroxyl radical-induced oxidative DNA damage was generated in arsenic trioxide-treated keratinocyes (10). In addition, elevated levels of 8-OH-dG were observed in the urine of the patients with arsenic poisoning $(8,9)$. In the present study, we also detected an increased level of 8-OH-Gua in the DNA of NCTC treated with a physiologically relevant concen- 


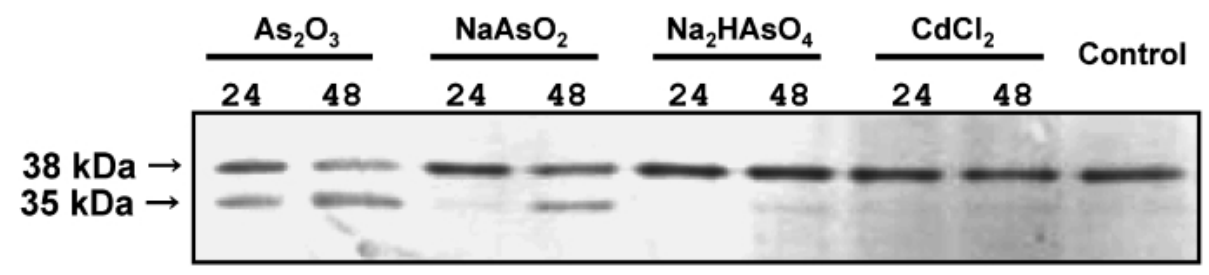

Fig. 3. Immunoblotting of mOGG1 in NCTC treated with arsenic trioxide $(10 \mu \mathrm{M})$, sodium arsenite $(10 \mu \mathrm{M})$, sodium arsenate $(10 \mu \mathrm{M})$, and cadmium chloride $(10 \mu \mathrm{M})$ for 24 and $48 \mathrm{~h}$. Upper bands $(38 \mathrm{kDa})$ represent normal mOGG1 and lower bands $(35 \mathrm{kDa})$ are cleaved mOGG1. Control refers to data of DMSO-treated NCTC $(24 \mathrm{~h}) . \mathrm{As}_{2} \mathrm{O}_{3}$, arsenic trioxide; $\mathrm{NaAsO}_{2}$, sodium arsenite; $\mathrm{Na}_{2} \mathrm{HAsO}_{4}$; sodium hydrogen arsenate; $\mathrm{CdCl}_{2}$, cadmium chloride.

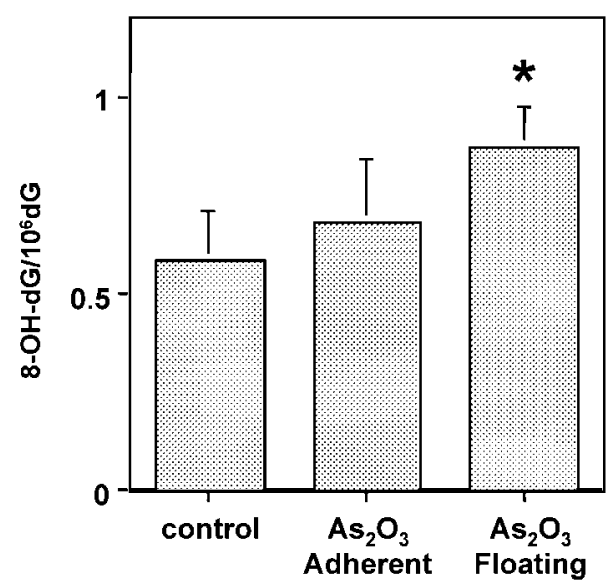

Fig. 4. Effect of arsenic trioxide on $8-\mathrm{OH}-\mathrm{dG}$ formation in NCTC cells. The results represent means $\pm \mathrm{SD}, \mathrm{n}=3 .{ }^{*} \mathrm{p}<0.05$, significantly higher than the control group.

tration $(10 \mu \mathrm{M})$ of arsenic trioxide.

It is noteworthy that the accumulation level of $8-\mathrm{OH}-\mathrm{Gua}$ depends on the balance between the generation and repair of $8-\mathrm{OH}-\mathrm{Gua}$. Hence, the DNA repair activity and the 8-OH-Gua generation must both be considered. In fact, several recent reports have attributed the mechanism of DNA damage accumulation to the inhibition of DNA repair system as described below.

We and other groups have reported that some carcinogenic agents, such as cadmium compounds and diesel exhaust particles, disturbed 8-OH-Gua repair, leading to the subsequent accumulation of $8-\mathrm{OH}-\mathrm{Gua}$ $(16,17,20)$. As for arsenic compounds, we also previously reported that sodium arsenite decreased the $8-\mathrm{OH}-$ Gua base excision repair activity and increased the 8-OH-Gua level in the DNA of culture cells (6). Another group also indicated that arsenic compounds increased the accumulation of oxidative DNA damage along with the interference of repair systems (18). Besides the DNA repair system, defense systems against ROS, such as superoxide dismutase (SOD) and GSH-Px, were also disrupted by arsenic compounds (21). These findings suggest that arsenic compounds disrupt the defense mechanisms, including DNA repair systems, against oxidative stresses. However, the detailed mechanisms are still unknown.

OGG1, one of the main repair enzymes for 8-OHGua in mammalian cells, was cloned in 1996 (22-24). Although other repair enzymes besides OGG1 could also participate, OGG1 might play an important and central role in 8-OH-Gua repair. Therefore, analysis of OGG1 expression might provide useful information to understand the 8-OH-Gua repair systems. In the present study, the fragmentation of mOGG1 was detected in NCTC treated with arsenic compounds. Similar results were obtained in our previous studies, in which we detected the fragmentation of mOGG1 in carcinogentreated mouse liver or during caspase-dependent apoptosis in cultured mouse nonparenchymal hepatocytes $(19,25)$. In those cases and the present study, the 8-OH-Gua accumulation was increased, suggesting that the fragmentation of OGG1 resulted in the increased level of 8-OH-Gua accumulation. The smaller mOGG1 was suggested to be a product of posttranscriptional modification, rather than alternative splicing (19). We propose two mechanisms of mOGG1 fragmentation. First, the fragmentation might be due to caspase activity, because arsenic trioxide reportedly induces apoptosis through caspase-3 activation (26). Secondly, as arsenic trioxide produces more ROS in comparison to other arsenic compounds (27), we can speculate that mOGG1 is excised by ROS. The most notable point of our present results is that mOGG1 fragmentation occurred at the early stage of DNA repair inhibition, suggesting that mOGG1 fragmentation might be responsible for DNA repair inhibition. On the other hand, another possible mechanism for the inhibition of OGG1 activity was suggested by other groups. Recently, Youn et al. reported that the cadmium-mediated decrease in hOGGl transcription was the result of decreased binding of the transcription factor Sp1 to the hOGGl promoter (28). Whether the same mechanism also occurs in arsenic compound-treated cells or animals remains unknown. Further studies are required to clarify the detailed mechanism of DNA repair inhibition.

In conclusion, our results suggest that arsenic 
compounds increased the accumulation of $8-\mathrm{OH}-\mathrm{Gua}$ by the cleavage of its repair enzyme, mOGG1.

Acknowledgements: This work was supported by a grant from the University of Occupational and Environmental Health, Japan, and a Grant-in-Aid from the Ministry of Education, Culture, Sports, Science and Technology of Japan.

\section{References}

1 Grimsrud TK, Berge SR, Haldorsen T, Andersen A. Can lung cancer risk among nickel refinery workers be explained by occupational exposures other than nickel? Epidemiology. 2005; 16: 146-54.

2 Rossman TG, Uddin AN, Burns FJ. Evidence that arsenite acts as a cocarcinogen in skin cancer. Toxicol Appl Pharmacol. 2004; 198: 394-404.

3 Hopenhayn-Rich C, Biggs ML, Smith AH. Lung and kidney cancer mortality associated with arsenic in drinking water in Cordoba, Argentina. Int J Epidemiol. 1998; 27: 561-9.

4 Hernandez-Zavala A, Cordova E, Del Razo LM, Cebrian M. E, Garrido E. Effects of arsenite on cell cycle progression in a human bladder cancer cell line. Toxicology. 2005; 207: 49-57.

5 Lu SN, Chow NH, Wu WC, Chang TT, Huang WS, Chen SC, Lin CH, Carr BI. Characteristics of hepatocellular carcinoma in a high arsenicism area in Taiwan: a case-control study. J Occup Environ Med. 2004; 46: 437-41.

6 Mei N, Kunugita N, Hirano T, Kasai H. Acute arseniteinduced 8-hydroxyguanine is associated with inhibition of repair activity in cultured human cells. Biochem Biophys Res Commun. 2002; 297: 924-30.

7 Fujino Y, Guo X, Liu J, Matthews IP, Shirane K, Wu K, Kasai H, Miyatake M, Tanabe K, Kusuda T, Yoshimura T; Japan Inner Mongolia Arsenic Pollution Study Group. Chronic arsenic exposure and urinary 8-hydroxy-2'-deoxyguanosine in an arsenic-affected area in Inner Mongolia, China. J Expo Anal Environ Epidemiol. 2005; 15: 147-52.

8 Yamauchi H, Aminaka Y, Yoshida K, Sun G, Pi J, Waalkes MP. Evaluation of DNA damage in patients with arsenic poisoning urinary 8-hydroxydeoxyguanine. Toxicol Appl Pharmacol. 2004; 198: 291-6.

9 Schwerdtle T, Walter I, Mackiw I, Hartwig A. Induction of oxidative DNA damage by arsenite and its trivalent and pentavalent methylated metabolites in cultured human cells and isolated DNA. Carcinogenesis. 2003; 24 : 967-74.

10 Shi H, Hudson LG, Ding W, Wang S, Cooper KL, Liu S, Chen Y, Shi X, Liu KJ. Arsenite causes DNA damage in keratinocytes via generation of hydroxyl radicals. Chem Res Toxicol. 2004; 17: 871-8.

11 Gurr JR, Yih LH, Samikkannu T, Bau DT, Lin SY, Jan KY. Nitric oxide production by arsenite. Mutat Res. 2003; 533: 173-82.

12 Chien YH, Bau DT, Jan KY. Nitric oxide inhibits DNAadduct excision in nucleotide excision repair. Free Radic
Biol Med. 2004; 36: 1011-7.

13 Kasai H, Nishimura S. Hydroxylation of deoxyguanosine at the $\mathrm{C}-8$ position by ascorbic acid and other reducing agents. Nucleic Acids Res. 1984; 12: 2137-45.

14 Tchou J, Kasai H, Shibutani S, Chung MH, Laval J, Grollman AP, Nishimura S. 8-Oxoguanine (8-hydoxyguanine) DNA glycosylase and its substrate specificity. Proc Natl Acad Sci USA. 1991; 88: 4690-4.

15 Boiteux S, Gajewski E, Laval J, Dizdaroglu M. Substrate specificity of the Escherichia coli Fpg protein (formamidepyrimidine-DNA glycosylase): excision of purine lesions in DNA produced by ionizing radiation or photosensitization. Biochemistry. 1992; 31: 106-10.

16 Hirano T, Yamaguchi Y, Kasai H. Inhibition of 8hydroxyguanine repair in testes after administration of cadmium chloride to GSH-depleted rats. Toxicol Appl Pharmacol. 1997; 147: 9-14.

17 Porter DW, Yakushiji H, Nakabeppu Y, Sekiguchi M, Fiyash MJ, Kasprzak KS. Sensitivity of Escherichia coli (MutT) and human (MTH1) 8-oxo-dGTPases to in vitro inhibition by the carcinogenic metals, nickel(II), copper (II), cobalt(II) and cadmium(II). Carcinogenesis. 1997; 18: 1785-91.

18 Hartwig A, Blessing H, Schwerdtle T, Walter I. Modulation of DNA repair processes by arsenic and selenium compounds. Toxicology. 2003; 193: 161-9.

19 Hirano $T$, Kudo H, Doi $Y$, Nishino $T$, Fujimoto $S$, Tsurudome Y, Ootsuyama Y, Kasai H. Detection of a smaller, 32-kDa 8-oxoguanine DNA glycosylase 1 in $3^{\prime}$ methyl-4-dimethylamino-azobenzene-treated mouse liver. Cancer Sci. 2004; 95: 118-22.

20 Tsurudome Y, Hirano T, Yamato H, Tanaka I, Sagai M, Hirano H, Nagata N, Itoh H, Kasai H. Changes in levels of 8-hydroxyguanine in DNA, its repair and OGG1 mRNA in rat lungs after intratracheal administration of diesel exhaust particles. Carcinogenesis. 1999; 20: 1573-6.

21 Shen ZY, Shen WY, Chen MH, Shen J, Zeng Y. Reactive oxygen species and antioxidants in apoptosis of esophageal cancer cells induced by $\mathrm{As}_{2} \mathrm{O}_{3}$. Int $\mathrm{J}$ Mol Med. 2003; 11: 479-84.

22 Rosenquist TA, Zharkov DO, Grollman AP. Cloning and characterization of a mammalian 8-oxoguanine DNA glycosylase. Proc Natl Acad Sci USA. 1997; 94: 7429-34.

23 Radicella JP, Dherin C, Desmaze C, Fox MS, Boiteux S. Cloning and characterization of $h O G G 1$, a human homolog of OGG1 gene of Saccharomyces cerevisiae. Proc Natl Acad Sci USA. 1997; 94: 8010-5.

24 Tani M, Shinmura K, Kohno T, Shiroishi T, Wakana S, Kim SR, Nohmi T, Kasai H, Takenoshita S, Nagamachi Y, Yokota J. Genomic structure and chromosomal localization of the mouse $O g g 1$ gene that is involved in the repair of 8-hydroxyguanine in DNA damage. Mamm Genome. 1998; 9: 32-7.

25 Hirano T, Kawai K, Ootsuyama Y, Orimo H, Kasai H. Detection of a mouse OGG1 fragment during caspasedependent apoptosis: oxidative DNA damage and apoptosis. Cancer Sci. 2004; 95: 634-8.

26 Park JW, Cjoi YJ, Jang MA, Baek SH, Lim JH, Passaniti T, Kwon TK. Arsenic trioxide induces G2/M growth 
arrest and apoptosis after caspase- 3 activation and bcl-2 phosphorylation in promonocytic U937 cells. Biochem Biophys Res Commun. 2002; 286: 726-34

27 Tsai SH, Hsieh MS, Chen L, Liang YC, Lin JK, Lin SY. Suppression of Fas ligand expression on endothelial cells by arsenite through reactive oxygen species. Toxicol
Lett. 2001; 123: 11-9

28 Youn CK, Kim SH, Lee do Y, Song SH, Chang IY, Hyun. JW, Chung MH, You HJ. Cadmium down-regulates human OGG1 through suppression of Sp1 activity. J Biol Chem 2005; 280: 25185-95. 